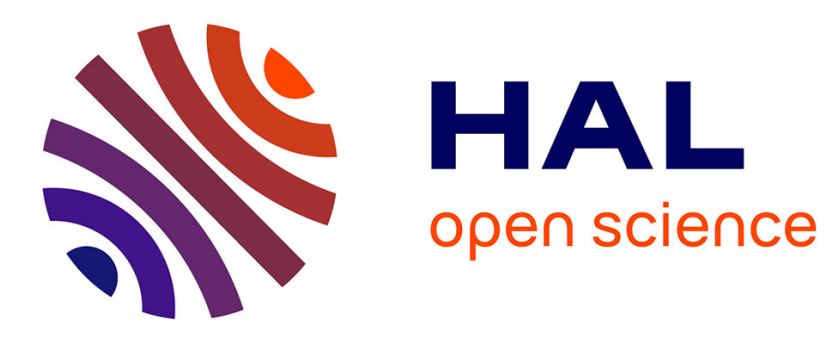

\title{
Laminar burning velocities of premixed nitromethane/air flames: an experimental and kinetic modeling study
}

Pierre Brequigny, G. Dayma, F. Halter, Christine Mounaïm-Rousselle, T. Dubois, P. Dagaut

\section{To cite this version:}

Pierre Brequigny, G. Dayma, F. Halter, Christine Mounaïm-Rousselle, T. Dubois, et al.. Laminar burning velocities of premixed nitromethane/air flames: an experimental and kinetic modeling study. Proceedings of the Combustion Institute, 2015, 35 (1), pp.703-710. 10.1016/j.proci.2014.06.126 . hal-02073747

\section{HAL Id: hal-02073747 \\ https://hal-univ-orleans.archives-ouvertes.fr/hal-02073747}

Submitted on 7 Jun 2019

HAL is a multi-disciplinary open access archive for the deposit and dissemination of scientific research documents, whether they are published or not. The documents may come from teaching and research institutions in France or abroad, or from public or private research centers.
L'archive ouverte pluridisciplinaire HAL, est destinée au dépôt et à la diffusion de documents scientifiques de niveau recherche, publiés ou non, émanant des établissements d'enseignement et de recherche français ou étrangers, des laboratoires publics ou privés. 


\title{
Laminar burning velocities of premixed nitromethane/air flames:
} an experimental and kinetic modeling study

\author{
P. Brequigny ${ }^{1}$, G. Dayma ${ }^{2}$, F. Halter ${ }^{1}$, C. Mounaïm-Rousselle ${ }^{1}$, T. Dubois ${ }^{3}$, P. Dagaut ${ }^{2}$ \\ ${ }^{1}$ University of Orléans, PRISME, 8 Rue Léonard de Vinci - 45072 Orléans cedex 2, France \\ ${ }^{2}$ CNRS-INSIS, 1C Avenue de la recherche scientifique - 45071 Orléans cedex 2, France \\ ${ }^{3}$ Centre de Recherche de Solaize, TOTAL Marketing \& Services, Solaize, France
}

\begin{abstract}
Due to its high lubricity, nitromethane is a fuel regularly used in model engine or more generally in race engine. The objective of this study is to improve our knowledge and understanding of the combustion of nitromethane for better evaluating its potential as fuel for automotive spark-ignition engines. To achieve this goal, unstretched laminar burning velocities of nitromethane-air mixtures were measured using spherical propagation methodology at $423 \mathrm{~K}$ over a pressure range from 0.5 to 3 bar and equivalence ratios from 0.5 to 1.3 . The data indicated a typical adverse effect of pressure on laminar burning velocities. Based on the work done by Zhang et al., Proc. Combust. Inst., 33 (2011) 407-414, a modified detailed kinetic model including 88 species and 701 reactions was proposed. Comparisons between experimental and simulated un-stretched laminar flame speed were made and showed good agreement. The new kinetic mechanism was also used to successfully simulate published experiments and rationalize the unusual occurrence of maximum flame speed in the fuellean region.
\end{abstract}




\section{Introduction}

Nitromethane, the simplest nitroparaffin fuel, is known as a high performance fuel additive for internal combustion engine [1]. Indeed, due to their high engine regime, model and dragster engines need to be well lubricated. In that case, the choice of the fuel is a key point more particularly in model engines which do not have a lubricant system. For many years, nitromethane has been used in these engines, usually blended with methanol [2]. Moreover, this fuel has been used as a reference molecule to understand the combustion mechanism of monopropellants [3]. Physical properties of nitromethane are well known [4] but only a few recent studies investigated its combustion characteristics through kinetic modeling. Glarborg et al. [5] developed a reaction mechanism for nitromethane decomposition at high temperatures and validated it with experimental shock tube measurements. Boyer and Kuo [3] developed a mechanism consisting of 47 species and 250 reactions at pressures from 30 to 150 bar. This study investigated the potential of nitromethane as monopropellant in space thrusters. The model showed that temperature and species profiles display three distinct regions. The decomposition of nitromethane to $\mathrm{CH}_{3}$ and $\mathrm{NO}_{2}$ takes place in the first region. In the second region, consumption of all intermediate species except $\mathrm{CH}_{4}$ and $\mathrm{NO}$ occurs. In the third region, temperature and species concentrations reach their thermodynamic equilibrium values. In that region, $\mathrm{CH}_{4}$ and $\mathrm{NO}$ are respectively fuel and oxidizer that allow reaching equilibrium composition. More recently, a detailed oxidation mechanism including 69 species and 314 reactions was developed by Tian et al. [6]. This mechanism was validated based on experimental study of a nitromethane premixed flame at 46.7 mbar and an equivalence ratio of 1.39 . The results showed that $\mathrm{N}_{2}$ and $\mathrm{NO}$ are the main nitrogenous products of the nitromethane flame. Moreover, the experiment displayed a number of unreported intermediate species compared to previous studies such as $\mathrm{C}_{3} \mathrm{H}_{4}, \mathrm{C}_{4} \mathrm{H}_{6}, \mathrm{C}_{4} \mathrm{H}_{8}, \mathrm{C}_{2} \mathrm{H}_{2} \mathrm{O}, \mathrm{C}_{2} \mathrm{H}_{4} \mathrm{O}, \mathrm{CH}_{3} \mathrm{CN}$, $\mathrm{H}_{2} \mathrm{C}=\mathrm{NH}=\mathrm{O}$ and $\mathrm{C}_{3} \mathrm{H}_{7} \mathrm{~N}$. However, since the mechanism developed by Boyer and Kuo is a simple high pressure model and Tian's model was only validated at one equivalence ratio, they are both too limited to model nitromethane combustion over a wide range of conditions. Therefore, Zhang et al. [7] developed a new kinetic model including 88 species and 701 reactions. To validate that model, mole fraction profiles of species and temperature profiles were measured in three premixed $\mathrm{CH}_{3} \mathrm{NO}_{2} / \mathrm{O}_{2} / \mathrm{Ar}$ 
flames at 46.55 mbar for equivalence ratios of 1.0, 1.5, and 2.0. Zhang et al. [7] also presented reaction pathways and showed that after the decomposition of nitromethane to $\mathrm{CH}_{3}$ and $\mathrm{NO}_{2}, 40 \%$ of $\mathrm{CH}_{3}$ is consumed by reaction with $\mathrm{NO}_{2}$. About $59 \%$ of the total consumption of $\mathrm{NO}_{2}$ is due to the reaction with $\mathrm{H}$ atom.

Finally, it is important to notice that no laminar flame speed of nitromethane/air mixtures has yet been reported in the literature. However, de Jaegere and van Tiggelen [8] already measured flame speeds of compounds containing nitrogen oxides. The authors observed completely different behaviors between nitromethane, methyl nitrite and methane-nitrogen dioxide mixtures and they attributed these differences to different binding energies. Their mixtures were highly concentrated (between 10 and $45 \%$ mol of $\mathrm{N}_{2}$ ) and it is then difficult from this study to evaluate the potential of nitromethane as a fuel-additive. Indeed, since the purpose of this study was to evaluate the potential of nitromethane as a fuel or additive in Spark-Ignition engines, we focus on the improvement of the kinetic model by Zhang et al. [7] to predict unstretched laminar burning velocities over a wide range of equivalence ratios and pressures. To achieve this goal, both experiments and simulations were carried out.

\section{Experimental Set-up}

The experiments were performed in a spherical stainless steel combustion chamber. The inner volume of the chamber is $4.2 \mathrm{~L}$ with an inner diameter of $200 \mathrm{~mm}$. The outer surface of the sphere is equipped with a heater wire resistance in order to heat the fresh gases to a maximum initial temperature of $473 \mathrm{~K}$. Experiments were carried out at initial pressures of $0.5,1,2$, and 3 bar. Equivalence ratios were calculated considering the following reaction: $\mathrm{CH}_{3} \mathrm{NO}_{2}+0.75\left(\mathrm{O}_{2}+3.78 \mathrm{~N}_{2}\right)=$ $\mathrm{CO}_{2}+1.5 \mathrm{H}_{2} \mathrm{O}+3.335 \mathrm{~N}_{2}$. Equivalence ratio influence was investigated in the range 0.5 to 1.3 . The equivalence ratio was defined taking into account the amount of oxygen provided by the fuel. The stoichiometric amount of $\mathrm{O}_{2}$ is $0.75 \mathrm{~mol}$ for $1 \mathrm{~mol}$ of nitromethane as specified by the global reaction.

Before filling the sphere with gases, a vacuum pump was used to evacuate the combustion chamber and reach a pressure $<0.003$ bar. Nitromethane and air were injected by a Coriolis mass flow meter and a thermal flow meter, respectively. In this experiment, air was directed to the exit of the 
Coriolis mass flow meter in order to convey the liquid nitromethane. The composition of the synthetic air used was $79.1 \% \mathrm{~N}_{2}$ and $20.9 \% \mathrm{O}_{2}$. Before being introduced in the sphere, the inlet valve heated the nitromethane-air mixture up to $423 \mathrm{~K}$ to fully vaporize nitromethane. The sphere walls were also heated up to $423 \mathrm{~K}$ to avoid condensation. The sphere is equipped with a fan to obtain a perfectly homogeneous mixture. The fan was stopped $50 \mathrm{~s}$ before the ignition to avoid any perturbation that could disturb the flame propagation. The maximum deviation between the effective initial pressure inside the combustion chamber and the required initial pressure was about $0.5 \%$. The temperature fluctuation of the prepared mixture was within $2 \mathrm{~K}$ from the desired initial temperature. Two tungsten electrodes (1.5 mm diameter), with a $1 \mathrm{~mm}$ gap, linked to a conventional capacitive discharge ignition system were used. In the present experiments, the time charge of the ignition coil was set to $3.5 \mathrm{~ms}$ which corresponds to a discharge energy of $100 \mathrm{~mJ}$. More details can be found concerning the device in [9].

To measure laminar flame speeds, the shadowgraphy technique was used. Optical access into the chamber was provided by two opposite and transparent windows (diameter $82 \mathrm{~mm}$ ). A LED illuminator was used to provide continuous and incoherent light with a wavelength of $528 \mathrm{~nm}$. A parallel light was obtained using a pinhole (diameter $3 \mathrm{~mm}$ ), placed at the focal point of the objective, and a planoconvex lens (diameter $70 \mathrm{~mm}$, focal length $1000 \mathrm{~mm}$ ). Then, the beam is displayed on a screen after illuminating the chamber. Instantaneous images were recorded using a Photron FASTCAM APX high-speed video camera operating at 6000 images per second. The temporal evolution of the expanding spherical flame was then processed. Measurements are limited to flames with diameter greater than $6.5 \mathrm{~mm}$ to avoid ignition effect and lower than $20 \mathrm{~mm}$ which corresponds to a burned gas volume less than $1 \%$ of sphere volume. Therefore the pressure in the chamber can be considered constant during measurements.

From image post-processing, the temporal flame front radius evolution was obtained. Images were postprocessed using a MATLAB routine after background substraction. For each image, the transition between luminous and dark zones was fitted by a circle. This transition corresponds to the maximum density gradient. Then, the laminar flame speed $V_{s}$ was calculated from the time derivative of the 
radius $r_{f}$. A non-linear methodology proposed by Kelley and Law [10] was used to estimate the unstretched laminar flame velocity $V_{s}{ }^{0}$ :

$\left(\frac{V_{s}}{V_{s}^{0}}\right)^{2} \ln \left(\frac{V_{s}}{V_{s}^{0}}\right)^{2}=-\frac{2 L_{b} K}{V_{s}^{0}}$

where $K$ is the stretch rate impacting the flame and $L_{b}$ is the Markstein length for burned gas. The flame stretch rate can be defined as the temporal rate of change of a surface element $A[11]$ :

$K=\frac{1}{A} \frac{d A}{d t}$

When considering a spherical outwardly expanding flame, the previous equation can be simplified to the following expression:

$K=\frac{2}{r_{f}} \frac{d r_{f}}{d t}$

The unstretched laminar flame velocity $V_{s}^{0}$ is obtained from the non-linear model. To determine the fundamental unstretched laminar burning velocity $S_{L}{ }^{0}$, the effect of the expansion factor $\left(\rho_{b} / \rho_{u}\right)$ has to be considered:

$S_{L}^{0}=\frac{\rho_{b}}{\rho_{u}} V_{s}^{0}$

where $\rho_{b}$ and $\rho_{u}$ are the densities of the burned and the unburned gases respectively. These densities were calculated using the EQUIL code [12] from CHEMKIN package.

\section{Kinetic Modeling}

The presently measured experimental laminar burning velocities were used to improve the recent detailed kinetic mechanism proposed by Zhang et al. [7]. The original mechanism lays on previous works by Glarborg's team ([5], [13-15]). It was developed to predict species profiles measured in a premixed nitromethane/oxygen/argon flame stabilized on a flat flame burner at low pressure (46.55 mbar). To reproduce our experimental data obtained at pressures ranging from 0.5 to 3 bar, several rate 
constants from the original mechanism were modified to take into account their pressure dependency. To do so, the rate constant at 1 bar was chosen and taken from the same author as in the original mechanism when available. The original and updated rate constants are given as Supplemental material. Moreover, since $\mathrm{HCO}+\mathrm{M}=\mathrm{H}+\mathrm{CO}+\mathrm{M}$ is strongly pressure dependent, it was necessary to use the rate constant recently proposed by Yang et al. [16] with a Troe fitting to represent our data over the entire pressure range. Finally, three rate constants were really modified (i.e. taken from another reference). These rate constants are gathered in Table 1 and the newly proposed mechanism is now able to reproduce our experimental laminar burning velocities as well as the species profiles obtained by Zhang et al. [7]. This last comparison is presented in Figure 1 and it can be seen that the updated model (full lines) gives almost the same satisfactory agreement as the original version (dashed-dotted lines). This new detailed kinetic mechanism, involving 88 species and 701 reactions (same as the original model), is available as supplemental material and from the authors.

To model the unstretched freely propagating flame, the PREMIX [20] code from the CHEMKIN package was used. All these calculations were performed with the same convergence criteria (GRAD $=0.05$ and $\mathrm{CURV}=0.05$ ) which allow obtaining a solution with ca. 300 meshes. With such a number of meshes, the accuracy of the calculated solution was better than $2.5 \%$ (this value was obtained by comparing the laminar burning velocities calculated at the last step and at the previous one).

\section{Results and Discussion}

Figure 2 shows the unstretched laminar burning velocity $S_{L}{ }^{0}$ versus equivalence ratio over the entire tested pressure range: increasing the pressure from 0.5 to 3 bar leads to a decrease of the maximum laminar burning velocity by $40 \%$. From these experimental measurements, it can be seen that the maximum $S_{L}{ }^{0}$ occurs in the fuel-lean region for an equivalence ratio around 0.75 regardless to the pressure. This behavior is very different from methane as can be seen from Figure $3 b$ ) where $\mathrm{CH}_{4} /$ air laminar burning velocities are reported under the same experimental conditions. Additionally, it should be noted that it was not possible to ignite mixtures with an equivalence ratio lower than 0.6 for pressure greater than 2 bar. 
Our experimental results were compared to calculations performed using the mechanism developed by Zhang et al. [7] taking the pressure into account. This comparison is shown as dashed lines in Figure 3 for the four different pressures. It appears that Zhang's kinetic model well captures the variation of the unstretched laminar burning velocity as a function of equivalence ratio but overestimates the laminar burning velocities by more than $10 \mathrm{~cm} / \mathrm{s}$ at the maximum laminar burning velocity, e.g. $11 \mathrm{~cm} / \mathrm{s}$ at $\varphi=0.7$ and $p=0.5$ bar. Improvements were obtained modifying the rate constants of three reactions (Table 1). The new calculated laminar burning velocities are presented as full lines in Figure 3 for nitromethane and dotted lines for methane (methane's laminar burning velocities are also well reproduced by our model). The equivalence ratio at which the laminar burning velocity is maximum is well reproduced by the model. The discrepancy between experimental and calculated laminar burning velocities is now better, i.e. $2.6 \mathrm{~cm} / \mathrm{s}$ at $\varphi=0.7$ and $\mathrm{p}=0.5 \mathrm{bar}$, and even less when the pressure increases. At high equivalence ratio, typically for $\varphi=1.3$, the laminar burning velocity is still slightly over-estimated, particularly at high pressure.

In order to explain why the maximum flame speed is obtained around $\varphi=0.75$, reaction rate analyses were performed at different equivalence ratios using our new kinetic mechanism. Reaction pathways presented Figure 4 were calculated integrating each reaction rate as a function of the temperature. In this figure, the thickness of the arrows is proportional to these integrated reaction rates. According to our mechanism, nitromethane is almost exclusively (94\%) unimolecularly decomposed through $\mathrm{CH}_{3} \mathrm{NO}_{2}+\mathrm{M}=\mathrm{CH}_{3}+\mathrm{NO}_{2}+\mathrm{M}$. Methyl radicals produced during this first step can react in four different ways:

- $27 \%$ of them abstract $\mathrm{H}$ atoms from different molecules of the system and yield methane. This methane entirely gives methyl back by $\mathrm{H}$-abstraction with $\mathrm{OH}$.

- $\quad 15 \%$ react with $\mathrm{CH}_{3}$ itself or $\mathrm{CH}_{2}$ or $\mathrm{CH}$ and produce $\mathrm{C}_{2}$ species. All these $\mathrm{C}_{2}$ species yield vinyl radicals that will produce $\mathrm{C}_{2} \mathrm{H}_{2}, \mathrm{CH}_{2} \mathrm{CHO}$ and $\mathrm{CH}_{2} \mathrm{O}$.

- $\quad 16 \%$ react with $\mathrm{OH}$ and form $\mathrm{CH}_{2} \mathrm{OH}$ and water $\left(\mathrm{CH}_{3}+\mathrm{OH}=\mathrm{CH}_{2} \mathrm{OH}+\mathrm{H}_{2} \mathrm{O}\right)$.

- Finally, 34\% of the methyl react with $\mathrm{NO}_{2}$, both products of the initiation reaction, yielding methoxy radicals and nitric oxide $\left(\mathrm{CH}_{3}+\mathrm{NO}_{2}=\mathrm{CH}_{3} \mathrm{O}+\mathrm{NO}\right)$. 
$\mathrm{CH}_{3} \mathrm{O}$ mainly produce formaldehyde; $62 \%$ by $\beta$-scission $\left(\mathrm{CH}_{3} \mathrm{O}+\mathrm{M}=\mathrm{CH}_{2} \mathrm{O}+\mathrm{H}+\mathrm{M}\right)$ and $22 \%$ by H-abstraction with $\mathrm{NO}\left(\mathrm{CH}_{3} \mathrm{O}+\mathrm{NO}=\mathrm{CH}_{2} \mathrm{O}+\mathrm{HNO}\right)$. $\mathrm{CH}_{2} \mathrm{O}$ mostly reacts by $\mathrm{H}$-abstraction with $\mathrm{OH}$ while $\mathrm{HNO}$ mainly reacts with $\mathrm{CH}_{3}(35 \%), \mathrm{H}(31 \%)$ or $\mathrm{OH}(18 \%)$ to form $\mathrm{NO} . \mathrm{CH}_{2} \mathrm{OH}$ mainly reacts with $\mathrm{O}_{2}$ and yield formaldehyde.

Obviously, the unimolecular decomposition of the fuel is a controlling step for the flame to occur and, as a unimolecular reaction, its reaction rate only depends on the fuel concentration, the temperature and the pressure. In other words, for a given pressure, it only depends on the equivalence ratio in the fresh gases and the heat released by the flame.

Figure 5a) shows the evolution of the integrated net reaction rate of $\mathrm{CH}_{3} \mathrm{NO}_{2}+\mathrm{M}=\mathrm{CH}_{3}+\mathrm{NO}_{2}+\mathrm{M}$ as a function of equivalence ratio at 1 bar. This integrated net reaction rate was calculated integrating the local reaction rate as a function of the local temperature in the flame since the temperature profile depends on the equivalence ratio. Hence, this integrated net reaction rate can be compared from one equivalence ratio to another. Figure 5a) shows the dependence of the flame speed to the rate of this reaction: this rate increases from $\varphi=0.4$ to $\varphi=0.75$ and decreases from $\varphi=0.75$ to $\varphi=1.3$, almost as the laminar burning velocity does. However, since the fuel concentration increases with the equivalence ratio, one would expect the rate of this reaction to do so if the temperature profile in the flame front was the same from one equivalence ratio to another. Figure 5a) clearly shows this reaction rate decreases when $\varphi>0.75$. Thus, we can conclude that the heat released by these flames starts to decrease in the fuel-lean side, typically when $\varphi>0.75$ for all the tested pressures, and this makes the laminar burning velocity to decrease. The crucial importance of the heat released in the flame front regarding the laminar burning velocity is also illustrated by Fig. 5b). This figure compares the evolutions of the experimental laminar burning velocity to the maximum value of the temperature gradient versus the equivalence ratio at 1 bar. As can be seen from this comparison, these two values behave very similarly, confirming the dependence of the laminar burning velocity to the heat released.

Two of the most important reactions as far as heat release is concerned are $\mathrm{NO}_{2}+\mathrm{H}=\mathrm{NO}+\mathrm{OH}$ and $\mathrm{CH}_{2} \mathrm{O}+\mathrm{OH}=\mathrm{HCO}+\mathrm{H}_{2} \mathrm{O} . \mathrm{NO}_{2}+\mathrm{H}=\mathrm{NO}+\mathrm{OH}$ is the main pathway for the consumption of $\mathrm{NO}_{2}$ ( $67 \%$ of $\mathrm{NO}_{2}$ are consumed by this reaction while $27 \%$ are by $\left.\mathrm{CH}_{3}+\mathrm{NO}_{2}=\mathrm{CH}_{3} \mathrm{O}+\mathrm{NO}\right)$ and is one of 
the most exothermic reactions of this system with a significant reaction rate as can be seen from Figure 6 a) and b). So, the high heat of reaction and reaction rate of this reaction makes $\mathrm{NO}_{2}+\mathrm{H}=$ $\mathrm{NO}+\mathrm{OH}$ a major contributor to the heat released in the flame front. The other major contributor is $\mathrm{CH}_{2} \mathrm{O}+\mathrm{OH}=\mathrm{HCO}+\mathrm{H}_{2} \mathrm{O}$. Formaldehyde is an important intermediate, as depicted by Figure 4, which is mainly consumed by $\mathrm{H}$-abstraction by $\mathrm{OH}\left(61 \%\right.$ of $\mathrm{CH}_{2} \mathrm{O}$ are consumed by $\mathrm{OH}$ while $29 \%$ are by $\mathrm{CH}_{2} \mathrm{O}+\mathrm{H}=\mathrm{HCO}+\mathrm{H}_{2}$ ). Figure $6 \mathrm{~b}$ ) compares the highest normalized integrated net reaction rates as a function of the equivalence ratio. It can be seen from this figure that the normalized integrated net reaction rate of the initiation reaction $\left(\mathrm{CH}_{3} \mathrm{NO}_{2}+\mathrm{M}=\mathrm{CH}_{3}+\mathrm{NO}_{2}+\mathrm{M}\right)$ increases with the equivalence ratio. However, this step is hugely endothermic and the fraction of heat released by $\mathrm{NO}_{2}+\mathrm{H}=\mathrm{NO}+\mathrm{OH}$ and $\mathrm{CH}_{2} \mathrm{O}+\mathrm{OH}=\mathrm{HCO}+\mathrm{H}_{2} \mathrm{O}$ decreases when the equivalence ratio increases. In the meantime, the heat released by two other steps $\left(\mathrm{CH}_{3}+\mathrm{NO}_{2}=\mathrm{CH}_{3} \mathrm{O}+\mathrm{NO}\right.$ and $\left.\mathrm{H}_{2}+\mathrm{OH}=\mathrm{H}_{2} \mathrm{O}+\mathrm{H}\right)$, less exothermic than $\mathrm{NO}_{2}+\mathrm{H}=\mathrm{NO}+\mathrm{OH}$ and $\mathrm{CH}_{2} \mathrm{O}+\mathrm{OH}=\mathrm{HCO}+\mathrm{H}_{2} \mathrm{O}$, slightly increases accordingly to their normalized integrated net reaction rate. The increasing exothermicity of both of these reactions is not enough to compensate the decreasing exothermicity of both the others and the relative increasing demand of the initiation reaction. This decrease of the heat released in the flame front when the equivalence ratio increases explains why the laminar burning velocity decreases when $\varphi>0.75$. Finally, the relative decrease of the integrated net reaction rates of $\mathrm{NO}_{2}+\mathrm{H}=\mathrm{NO}+\mathrm{OH}$ and $\mathrm{CH}_{2} \mathrm{O}+\mathrm{OH}=\mathrm{HCO}+\mathrm{H}_{2} \mathrm{O}$ can be explained by the evolution of the integrated concentrations of $\mathrm{H}$ and $\mathrm{OH}$ as a function of the equivalence ratio. The concentrations were calculated from the respective mole fractions, the ideal gas law, the pressure and the local temperature in the flame. These concentrations were then integrated as a function of the local temperature, so that they can be compared from an equivalence ratio to another. These integrated concentrations for $\mathrm{H}$ and $\mathrm{OH}$ are plotted in Figure 7, and it can be seen that, when $\varphi$ $>0.7, \mathrm{OH}$ decreases while $\mathrm{H}$ stabilizes. This is responsible for the relative decrease of $\mathrm{NO}_{2}+\mathrm{H}=$ $\mathrm{NO}+\mathrm{OH}$ and $\mathrm{CH}_{2} \mathrm{O}+\mathrm{OH}=\mathrm{HCO}+\mathrm{H}_{2} \mathrm{O}$, and, at the end, for the decrease of the laminar burning velocity when $\varphi>0.75$.

The pressure dependence of the laminar burning velocity was also investigated according to the equivalence ratio. In that range of pressure, the flame speed was found to linearly depend on the 
pressure in a log-log scale. The pressure power exponents $(\alpha)$ were extracted from both our experimental and calculated data and reported versus the equivalence ratio on Figure 8. Error bars were obtained considering uncertainty on the pressure $(0.5 \%)$ and a statistical error of $3 \mathrm{~cm} / \mathrm{s}$ for the laminar burning velocity. All the experiments were repeated three times and this statistical error is the maximum deviation observed. From this figure, it can be seen that the pressure power exponent $\alpha$ oscillates around a mean value of ca. -0.25 in the lean side, with a local minimum in the pressure dependence close to the equivalence ratio at which the flame speed is maximum. Finally, for $0.7<\varphi<$ 1.3, the pressure dependence of the laminar burning velocity increases with the equivalence ratio.

\section{Conclusion}

The purpose of this study was to improve our knowledge and understanding of the combustion of nitromethane for better evaluating its potential as fuel for automotive spark-ignition engines. Unstretched laminar burning velocities of nitromethane-air mixtures were measured by using spherical propagation methodology at $423 \mathrm{~K}$ over the pressure range 0.5 to $3 \mathrm{bar}$, and equivalence ratios ranging from 0.5 to 1.3 . The data indicated a typical adverse effect of pressure on laminar burning velocities and an unusual occurrence of maximum flame speed in the fuel-lean region that was explained via detailed chemical kinetic modeling performed using an improved kinetic mechanism (88 species and 701 reactions) representing well the present experimental results.

\section{Acknowledgments}

This work has been made possible thanks to the financial support of Total S.A. The authors are grateful to P. Malbois for technical support. The authors thank Dr. K. Zhang for providing the original mechanism, thermochemistry, transport data, and experimental data on flat flame burner. The authors are also grateful to F. Deguillaume and Dr. J. Mollet for providing $\mathrm{CH}_{4}$ experimental data.

Supplemental material. The kinetic mechanism, thermochemistry, and transport data used in this work, a table with original and updated rate constants, and a table with all experimental values of laminar burning velocities. 


\section{References}

[1] E.S. Starkman, Ind. Eng. Chem. 51 (1959) 1477-1480.

[2] J. Papac and D. Dunn-Rankin, WSS/CI 2004 SPRING Meeting.

[3] E. Boyer and K.K. Kuo, Proc. Combust. Inst. 31 (2007) 2045-2053.

[4] A. Makovky, L. Lenji, L. Lexji, Chem. Rev. 58 (1958) 627-644.

[5] P. Glarborg, A.B. Bendtsen, J.A. Miller, Int. J. Chem. Kinet. 31 (1999) 591-602.

[6] Z. Tian, L. Zhang, Y. Li, T. Yuan, F. Qi, Proc. Combust. Inst. 32 (2009) 311-318.

[7] K. Zhang, Y. Li, T. Yuan, J. Cai, P. Glarborg, F. Qi, Proc. Combust. Inst. 33 (2011) 407-414.

[8] S. de Jaegere and A. van Tiggelen, Combust. Flame 3 (1959) 187-200.

[9] B. Galmiche, F. Halter, F. Foucher, P. Dagaut, Energy \& Fuels 25 (2011) 948-954.

[10] A.P. Kelley and C.K. Law, Combust. Flame 156 (2009) 1844-1851.

[11] S.M. Candel and T.J. Poinsot, Combust. Sci. Technol. 70 (1990) 1-15.

[12] A. E. Lutz, F. M. Rupley, R. J. Kee, Equil: A Chemkin implementation of Stanjan for computing chemical equilibria, Sandia National Laboratories Livermore, CA 94551.

[13] Ø. Skreiberg, P. Kilpinen, P. Glarborg, Combust. Flame 136 (2004) 501-508.

[14] P. Glarborg and L.L.B. Bentdsen, Energy \& Fuels 22 (2008) 291-296.

[15] C.L. Rasmussen and P. Glarborg, Combust. Flame 154 (2008) 529-545.

[16] X. Yang, T. Tan, P. Diévart, E.A. Carter, Y. Ju, $8^{\text {th }}$ U.S. National Combust Meeting (2013), 070RK-0163. 
[17] M.G. Bryukov, A.A. Kachanov, R. Timonnen, J. Seetula, J. Vandoren, O.M. Sarkisov, Chem. Phys. Lett. 208 (1993) 392-398.

[18] A.M. Dean, P.R. Westmoreland, Int. J. Chem. Kinet. 19 (1987) 207-228.

[19] Z.F. Xu, C.-H. Hsu, M.C. Lin, J. Chem. Phys.122 (2005) 234308.

[20] R.J. Kee, J.F. Grcar, M.D. Smooke, J.A. Miller, (1985). SAND85-8240. Livermore, CA: Sandia National Laboratories. 


\section{Figure captions}

Figure 1. Comparison between original (dashed-dotted line) and modified (full line) mechanism versus experimental data by Zhang et al. [7] at a) $\varphi=1$ and b) $\varphi=1.5$.

Figure 2. Unstretched laminar burning velocity versus equivalence ratio for $\mathrm{CH}_{3} \mathrm{NO}_{2} /$ air flames at $\mathrm{T}_{\mathfrak{u}}=$ $423 \mathrm{~K}$ and 0.5 bar $(\bullet), 1$ bar $(\diamond), 2$ bar $(\bullet)$, and 3 bar $(\square)$.

Figure 3. Comparisons between experimental (symbols) and calculated laminar burning velocities of $\mathrm{CH}_{3} \mathrm{NO}_{2} /$ air flames at $\mathrm{T}_{\mathrm{u}}=423 \mathrm{~K}$ versus the equivalence ratio using the mechanism by Zhang et al. [7] upgraded to 1 bar (dashed lines) and our new detailed kinetic mechanism (full lines) at four different pressures. Empty symbols and dotted line are respectively measured and calculated laminar burning velocities of $\mathrm{CH}_{4} /$ air mixtures at $\mathrm{T}_{\mathrm{u}}=423 \mathrm{~K}$ and $\mathrm{p}=1$ bar.

Figure 4. Main pathways for the decomposition of nitromethane (reaction rates were integrated over the reaction zone) at 1 bar and $\varphi=0.8$.

Figure 5. a) Evolution of the integrated net reaction rate of $\mathrm{CH}_{3} \mathrm{NO}_{2}+\mathrm{M}=\mathrm{CH}_{3}+\mathrm{NO}_{2}+\mathrm{M}$ versus equivalence ratio for $\mathrm{CH}_{3} \mathrm{NO}_{2}$ /air flames, b) comparison between the experimental laminar burning velocity and the maximum value of the temperature gradient versus the equivalence ratio at $T_{u}=423$ $\mathrm{K}$ and 1 bar.

Figure 6. Evolutions of a) the heat of reaction versus temperature for selected reactions and b) the normalized integrated net reaction rate of these reactions versus equivalence ratio for $\mathrm{CH}_{3} \mathrm{NO}_{2}$ /air flames at $\mathrm{T}_{\mathrm{u}}=423 \mathrm{~K}$ and 1 bar.

Figure 7. Evolution of the integrated concentrations of $\mathrm{H}$ and $\mathrm{OH}$ versus the equivalence ratio for $\mathrm{CH}_{3} \mathrm{NO}_{2} /$ air flames at $\mathrm{T}_{\mathrm{u}}=423 \mathrm{~K}$ and 1 bar.

Figure 8. Evolution of the pressure exponent $\alpha$ versus equivalence ratio for $\mathrm{CH}_{3} \mathrm{NO}_{2} /$ air flames at $\mathrm{T}_{\mathrm{u}}=$ $423 \mathrm{~K}$. 


\section{Tables}

Table 1. Original and modified rate constants $\left(\mathrm{A}, \mathrm{n}\right.$, and $\mathrm{E}$ in $\mathrm{k}=\mathrm{AT}^{\mathrm{n}} \exp (-\mathrm{E} /(1.9872 \mathrm{~T}))$ in $\mathrm{K}$, cal, mol, $\left.\mathrm{cm}^{3}, \mathrm{~s}^{-1}\right)$

\begin{tabular}{|l|r|r|r|r|r|r|r|r|}
\hline Reaction & \multicolumn{3}{|l|}{ Original rate constant } & \multicolumn{2}{l|}{ Ref. } & \multicolumn{2}{l|}{ Modified rate constant } & Ref. \\
\hline $\mathrm{HNO}+\mathrm{O}_{2}=\mathrm{HO}_{2}+\mathrm{NO}$ & $2.0 \mathrm{E}+13$ & 0.0 & 16000.0 & {$[13]$} & $2.2 \mathrm{E}+10$ & 0.0 & 9140.0 & {$[17]$} \\
$\mathrm{CH}_{3}+\mathrm{OH}=\mathrm{CH}_{2} \mathrm{OH}+\mathrm{H}$ & $4.4 \mathrm{E}+13$ & -0.3485 & -727.0 & {$[7]$} & $8.9 \mathrm{E}+18$ & -1.8 & 8067.0 & {$[18]$} \\
$\mathrm{HCO}+\mathrm{NO}=\mathrm{HNO}+\mathrm{CO}$ & $6.9 \mathrm{E}+12$ & 0.0 & 0.0 & {$[15]$} & $1.0 \mathrm{E}+08$ & 1.47 & -1760.0 & {$[19]$} \\
\hline
\end{tabular}


Figures

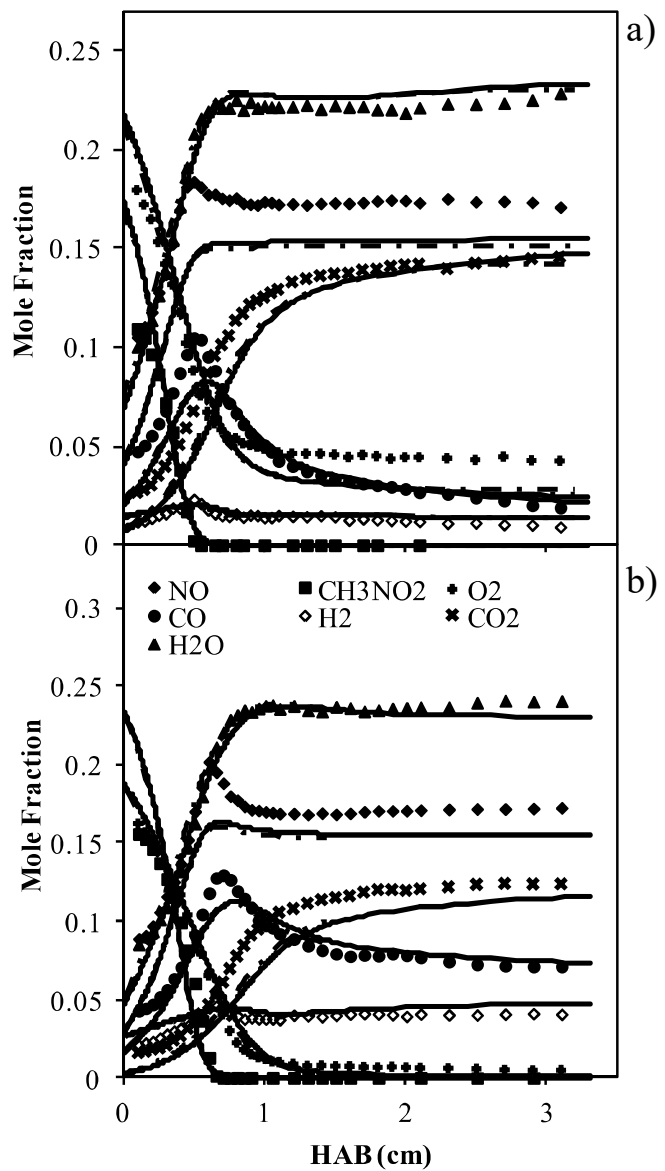

Figure 1. Comparison between original (dashed-dotted line) and modified (full line) mechanism versus experimental data by Zhang et al. [7] at a) $\varphi=1$ and b) $\varphi=1.5$. 


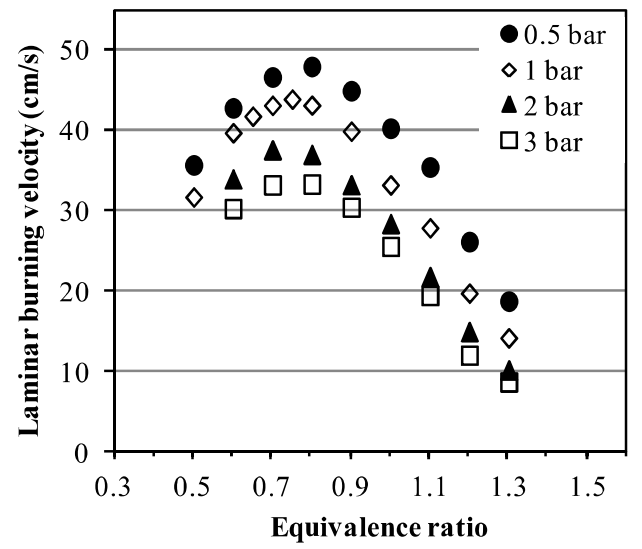

Figure 2. Unstretched laminar burning velocity versus equivalence ratio for $\mathrm{CH}_{3} \mathrm{NO}_{2} /$ air flames at $\mathrm{T}_{\mathfrak{u}}=$ $423 \mathrm{~K}$ and $0.5 \operatorname{bar}(\bullet), 1$ bar $(\diamond), 2$ bar $(\boldsymbol{\Lambda})$, and 3 bar $(\square)$. 


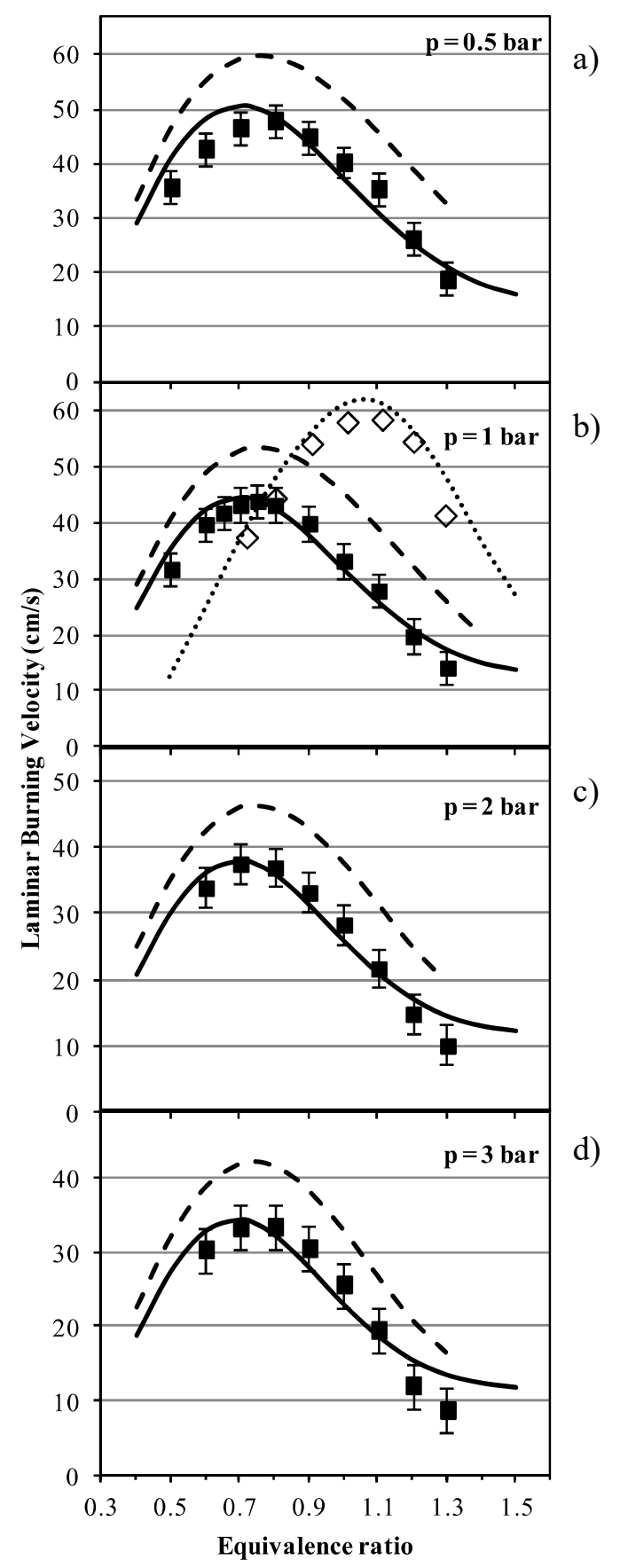

Figure 3. Comparisons between experimental (symbols) and calculated laminar burning velocities of $\mathrm{CH}_{3} \mathrm{NO}_{2} /$ air flames at $\mathrm{T}_{\mathrm{u}}=423 \mathrm{~K}$ versus the equivalence ratio using the mechanism by Zhang et al. [7] upgraded to 1 bar (dashed lines) and our new detailed kinetic mechanism (full lines) at four different pressures. Empty symbols and dotted line are respectively measured and calculated laminar burning velocities of $\mathrm{CH}_{4} /$ air mixtures at $\mathrm{T}_{\mathrm{u}}=423 \mathrm{~K}$ and $\mathrm{p}=1$ bar. 


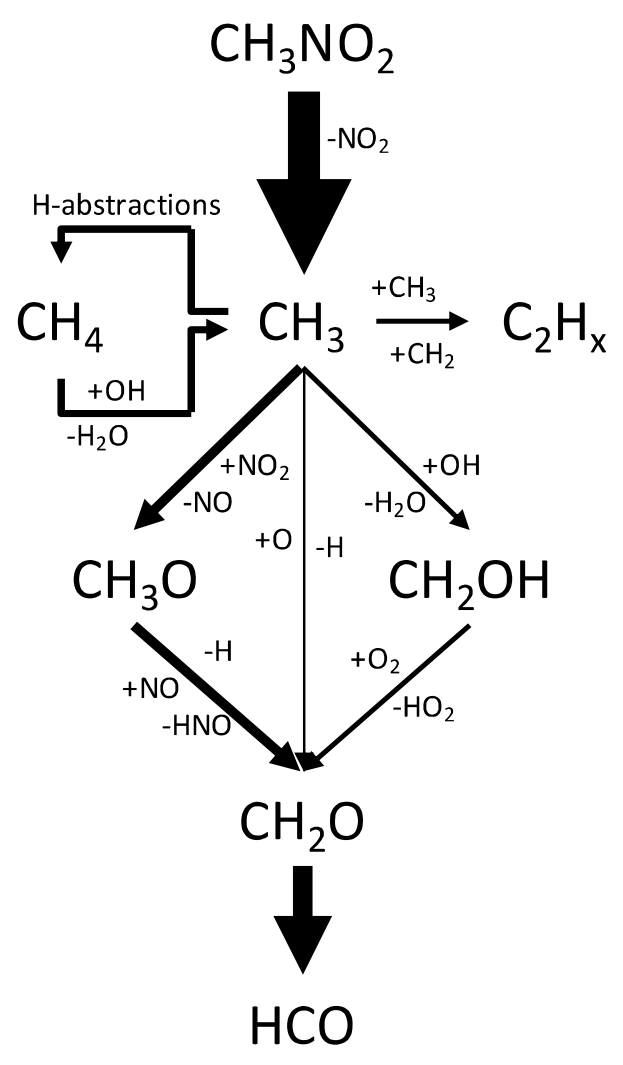

Figure 4. Main pathways for the decomposition of nitromethane (reaction rates were integrated over the reaction zone) at 1 bar and $\varphi=0.8$. 

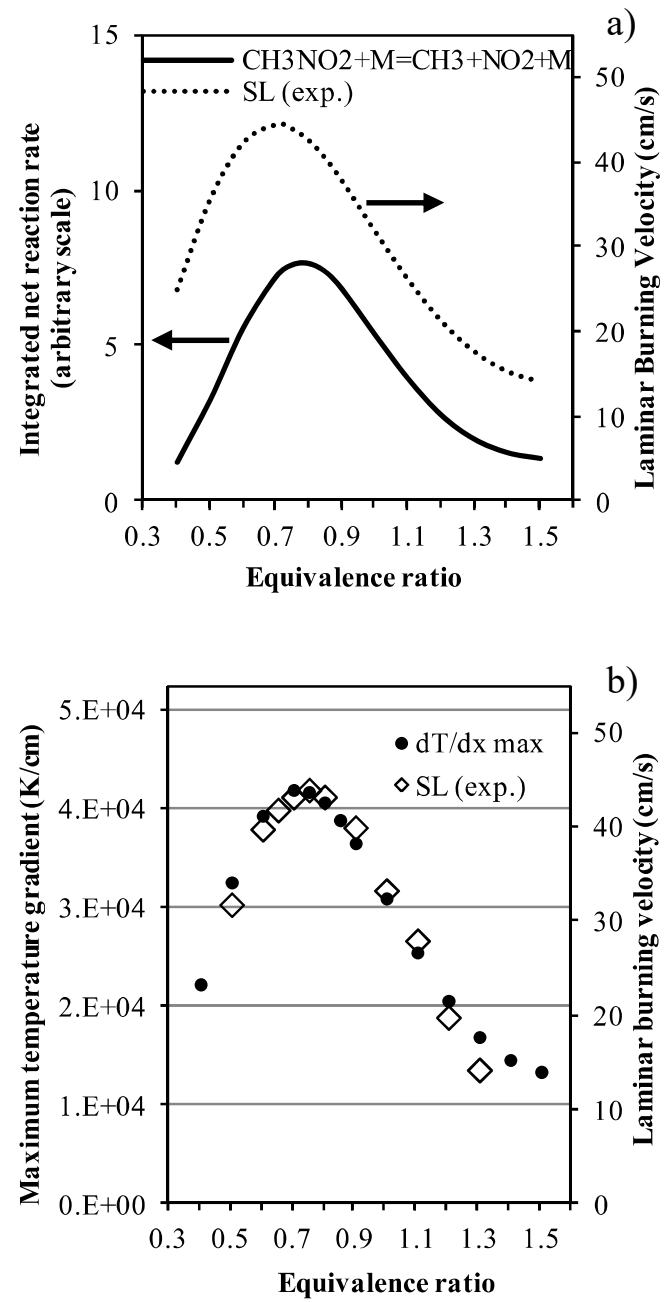

Figure 5. a) Evolution of the integrated net reaction rate of $\mathrm{CH}_{3} \mathrm{NO}_{2}+\mathrm{M}=\mathrm{CH}_{3}+\mathrm{NO}_{2}+\mathrm{M}$ versus equivalence ratio for $\mathrm{CH}_{3} \mathrm{NO}_{2}$ /air flames, b) comparison between the experimental laminar burning velocity and the maximum value of the temperature gradient versus the equivalence ratio at $T_{u}=423$ $\mathrm{K}$ and 1 bar. 

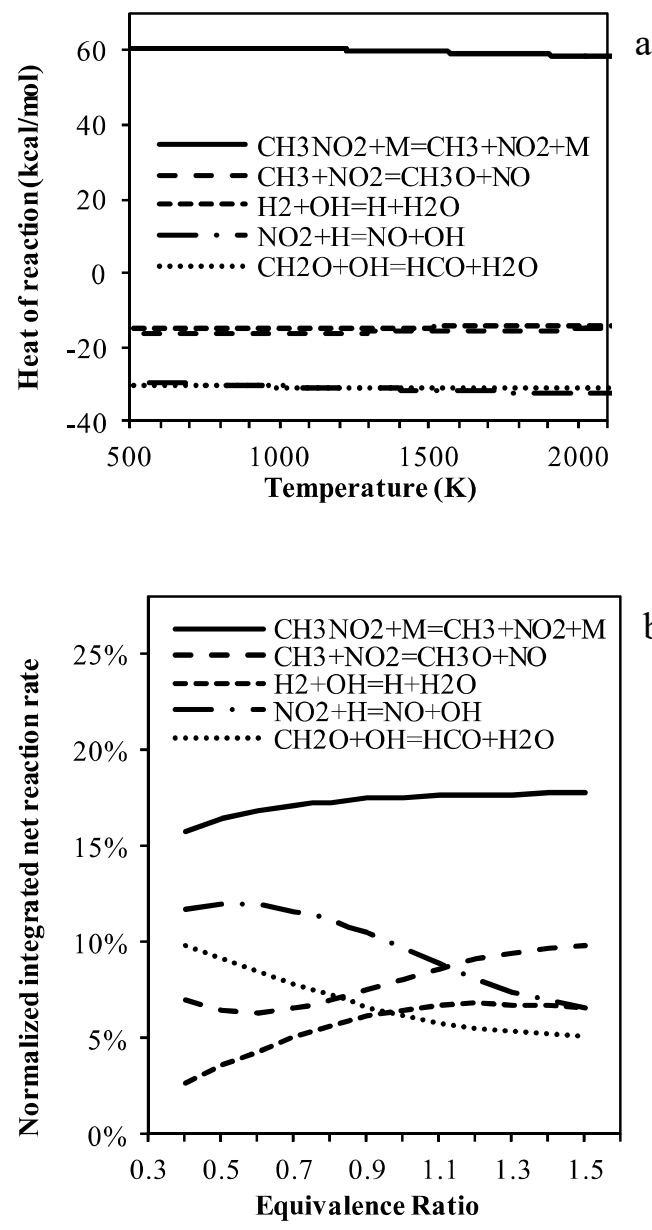

Figure 6. Evolutions of a) the heat of reaction versus temperature for selected reactions and b) the normalized integrated net reaction rate of these reactions versus equivalence ratio for $\mathrm{CH}_{3} \mathrm{NO}_{2} /$ air flames at $\mathrm{T}_{\mathrm{u}}=423 \mathrm{~K}$ and 1 bar. 


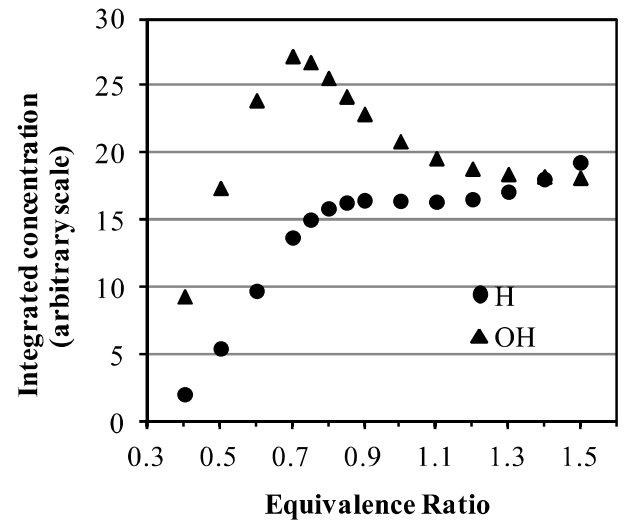

Figure 7. Evolution of the integrated concentrations of $\mathrm{H}$ and $\mathrm{OH}$ versus the equivalence ratio for $\mathrm{CH}_{3} \mathrm{NO}_{2} /$ air flames at $\mathrm{T}_{\mathrm{u}}=423 \mathrm{~K}$ and 1 bar. 


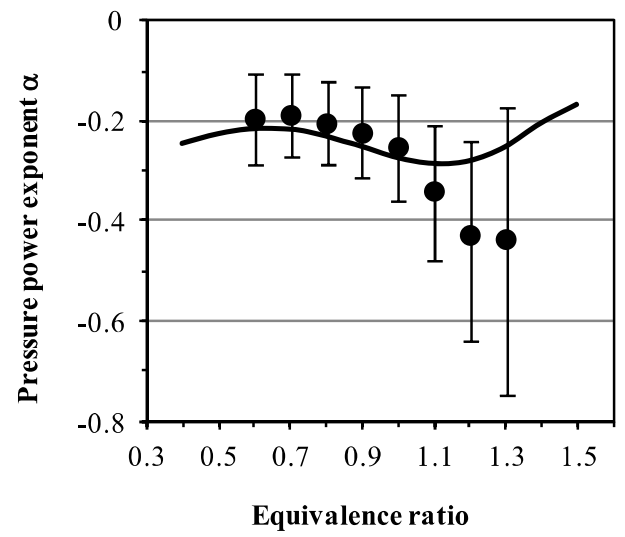

Figure 8. Evolution of the pressure exponent $\alpha$ versus equivalence ratio for $\mathrm{CH}_{3} \mathrm{NO}_{2} /$ air flames at $\mathrm{T}_{\mathrm{u}}=$ $423 \mathrm{~K}$. 